DOI: $10.4274 /$ tpa.46.10

\title{
Düzce'de birinci basamak sağlık hizmetleri üzerine bir değerlendirme: Ölü doğum ve bebek ölümleri
}

\section{An assessment on primary health care services in Düzce: Stillbirths and infant deaths}

\author{
Nasir Nesanir, Hilal Özcebe* \\ Düzce Toplum Sağlı̆̆ı Merkezi, Düzce, Türkiye \\ *Hacettepe Üniversitesi Tıp Fakültesi Halk Sağlı̆̆ı Anabilim Dalı, Ankara, Türkive
}

\section{Özet}

Amaç: Bu çalışmada Düzce'deki ölü doğumlar ve bebek ölümleri, sağlık hizmetlerinin değerlendirilmesi amacıyla incelenmiştir.

Gereç ve Yöntem: Bu çalışma 01.01.2005 ve 31.12.2008 tarihleri arasında Düzce İlinde meydana gelen 224 ölü doğum ve bebek ölümlerinin tamamını kapsayan tanımlayıcı bir çalışmadır. Annelerin \%86,7'si çalışmaya katılmıştır. Doğru ölüm hızlarını elde edebilmek için 01.01.2005 ve 31.12.2008 tarihleri arasındaki tüm ölümler hesaba alınmıştır. Araştırmada toplanan veriler SPSS for Windows 11.0 istatistik paket programında değerlendirilmiştir.

Bulgular: Bebek ölüm hızı 2005 ile 2008 yılları arasında Düzce Merkezde binde 10,3, Yığılca ilçesinde binde 23,6'dır. Ölü doğumu ve bebek ölümü olan ailelerin \%68,9'u alt, \%20,7'si orta, \%1,6'sı üst sosyal sınıftan ve \%8,8'i işsizdir. Ölü doğum ve bebek ölümü olan annelerin $\% 72$ 'sine gebelikleri öncesinde aile planlaması hakkında bilgi verilmemiştir.

Çıkarımlar: Ölü doğum ve bebek ölümü ile sosyoekonomik durum arasında olumsuz bir ilişki vardır. Üreme sağlığı ile ilgili sorunların olduğu tespit edilmiştir. (Türk Ped Arş 2011; 46: 55-62)

Anahtar sözcükler: Bebek ölümü, koruyucu sağlık hizmetleri, ölü doğum, sosyoekonomik etmenler

\section{Summary}

Aim: In this study, stillbirth and infant mortality in Düzce were examined for the purpose evaluation of health services.

Material and Method: This study is a descriptive study that covers all of stillbirth and infant mortality between 01.01.2005 and 31.12.2008 in Düzce. Between the same dates stillbirth and infant mortality were $224.86 .7 \%$ of mothers participated in the study. All deaths between 01.01.2005 and 31.12.2008 were taken into account to obtain accurate the mortality rates. The data collected in the study were evaluated using SPSS for Windows 11.0 statistical package program.

Results: The infant mortality of Center of Düzce was 10.3 per thousand and 23.6 per thousand in Yığılca region for the four years. Among the families who have stillbirth and infant mortality, $68.9 \%$ at low social class, $20.7 \%$ at middle social class, $1.6 \%$ at upper social class, and $8.8 \%$ is unemployed. Seventy two percent of the mothers were not informed about family planning during their pregnancy.

Conclusions: There is a negative relationship between socioeconomic status and stillbirth and infant mortality. There are problems with reproductive health. (Turk Arch Ped 2011; 46: 55-62)

Key words: Infant mortality, preventive health services, socioeconomic factors, stillbirth

\section{Giriş}

Sağlık Bakanlığı, 2003 yılında sosyalleştirmenin sağlık hizmetlerine yeterince yanıt vermediği ve birinci basamakta tedavi edilebilecek büyük bir hasta grubunun ikinci ve üçüncü basamak sağlık kurumlarına gittiği görüşleri ile birinci basamakta aile hekimliği uygulamasına geçilmesine karar vermiştir (1). 
Aile hekimliği uygulamasına geçiş süreci esaslarını belirleyen Aile Hekimliği Pilot Uygulaması Hakkında Kanun 09.12.2004 tarih ve 25665 sayılı Resmi Gazete'de yayımlanarak yürürlüğe girmiştir (2). Pilot il olarak belirlenen Düzce'de 16.09.2005 tarihinde aile hekimliği uygulamasına başlanmıştır. 31.12.2008 tarihine gelindiğinde 33 ilde daha sosyalizasyon terk edilerek birinci basamakta aile hekimliği uygulamasına geçilmiştir.

Ortalama 3500 kişiye bir hekimin ve bir aile sağlığı çalışanının (ebe, hemşire ya da sağlık memuru) düştüğü aile hekimliği uygulamasında aile hekimi ve aile sağlığı çalışanı kendilerine kayıtı kişilerin koruyucu sağlık hizmetleri ile birinci basamak tanı, tedavi ve rehabilite edici hizmetlerini vermekle yükümlüdürler (3).

Birinci basamak sağlık hizmetlerinde yapılan bu değişimin alt yapı ve insan gücü dağılımı, finansman, örgütlenme, ilk başvuru, eşgüdüm, kapsayıcılık, süreklilik, ulaşılabilirlik, toplum katılımı ve eşitlik gibi özelliklerin yanı sıra ölüm, doğurganlık ve hastalık gibi ölçütlerle değerlendirilmesi gerekmektedir (4).

Temel ölüm ölçütleri arasında yer alan ölü doğum ve bebek ölüm hızları sağlık hizmetleri ile ilgili girişimlere son derece duyarlıdır. Ölü doğum ve bebek ölümü sağlık hizmetlerinin izlenmesi, değerlendirilmesi, ileriye yönelik sağlık politikaların belirlenmesi ve kişilerin sosyoekonomik durumu ile yakından ilişkilidir (5).

Bu çalışmada Türkiye'de aile hekimliğine ilişkin ilk uygulamanın başladığı Düzce İlinde ölü doğumlar ve bebek ölümleri sağlık hizmetleri değerlendirilmesi amacıyla incelenmiştir.

\section{Gereç ve Yöntem}

Bu çalışma 01 Ocak 2005 ve 30 Eylül 2008 tarihleri arasında Düzce İlindeki ölü doğum ve bebek ölümlerinin tamamını kapsayan tanımlayıcı bir çalışmadır. Düzce II Sağlık Müdürlüğü kayıtlarına göre aynı tarihler arasında 224 ölü doğum ve bebek ölümü olmuştur (51 ölü doğum, 173 bebek ölümü). Ölü doğumu ve bebek ölümü olan annelere Düzce İ Sağlık Müdürlüğü tarafından merkezde iki ve ilçe toplum sağlığı merkezlerinde anket uygulama tekniği konusunda eğitim alan birer ebe yüz yüze anket uygulamak üzere görevlendirmiştir. Araştırma verisi NisanEkim 2008 tarihleri arasında toplanmıştır. Annelerin \%86,7'si (n=193) çalışmaya katılmıştır. Annelerin \%10,2'si $(n=24)$ adresinde bulunamamış, \%3,5'i $(n=7)$ ise çalışmaya katılmayı reddetmiştir.

Anket aracılığı ile çalışmada sosyal sınıf, sağlık güvencesi, ebeveyn eğitimi, annenin doğumdaki yaşı, aile hekimi ve aile sağlığı elemanının ev ziyaretinde bulunma durumu, isteyerek düşük yapma ve kendiliğinden düşük yapma durumu, gebeliği isteme durumu, bir önceki gebeliği ile son gebeliği arasındaki süre, şu an gebe olma durumu, üreme sağlığı, doğum öncesi, doğum ve doğum sonrası sağlık hizmetlerinden yararlanma durumu sorulmuştur.
Hanenin işe/mesleğe dayalı sosyal sınıfı, Boratav'ın Kentsel ve Kırsal Sosyal Sınıf Şeması'na göre belirlenmiştir (6). "Üst sosyal sınıf”ta küçük ve orta/büyük işveren, yüksek eğitimli olup kendi hesabına çalışanlar, yüksek eğitimli ücretliler, kapitalist çiftçi, zengin köylü, zengin çiftçi, rantiye; "orta sosyal sınıf"ta beyaz yakalı, mavi yakalı, küçük esnaf/zanaatkar, orta köylü; "alt sosyal sınıf”ta niteliksiz hizmet işçisi, küçük köylü, yoksul köylü, tarım işçisi ve "işsizler"de ise işsizler yer almaktadır.

Ölü doğumun olduğu tarih ve ölü doğumun nedeni; bebeğin doğum-ölüm tarihi, ölüm nedeni ve doğum ağırlığına ilişkin veri birinci, ikinci ve üçüncü basamak sağlık kurumlarından sağlık müdürlüğüne gönderilen "Bebek Ölümleri Bilgi Formu" kayıtlarından alınmıştır. Aynı zamanda Düzce İlinin 2005 ile 2008 yıllarına ait ölü doğum ve bebek ölüm hızlarının doğru hesaplanabilmesi için çalışmaya katılmayan/ulaşılamayan ve çalışmanın yürütüldüğü tarihten sonra (01.10.2008-31.12.2008 tarihleri arasında) meydana gelen ölü doğum ve bebek ölümlerinin verileri "Bebek Ölümleri Bilgi Formu"ndan alınmıştır.

Araştırmada toplanan veriler SPSS for Windows 11,0 istatistik paket programında sıklık ve yüzde dağılımları açısından değerlendirilerek tablolaştırılmıştır.

\section{Bulgular}

Düzce Merkez İlçesinde bebek ölüm hızı 2005-2008 yıllarında binde 5,5-11,8 arasında iken Yığılca İlçesinde ise binde 15,0-34,7 arasındadır (Tablo 1).

Ölü doğumu ve bebek ölümü olan annelerin \%8,3'ü doğum yaptığında 16-19, \%77,7'si 20-34 yaş ve \%9,8'i 35-44 yaş arasındadır. Ölü doğumu ve bebek ölümü olan annelerin \%56,5'i SSK'lı; \%18,7'si yeșil kartlı; \%9,3'ü Bağ-Kur'lu, \%3,1'i Emekli Sandığı'na bağlı idi ve \%12,4'ünün sağlık sigortası yoktur. Yeşil kartlı olan annelerin tamamı "alt sosyal" ya da "işsiz" sınıfında yer almaktadır. Sağlık güvencesi olmayan annelerin de \%93,3'ü "alt sosyal" ya da "işsiz" sınıfında yer almıştır. Ölü doğumu ve bebek ölümü olan annelerin \%91,2'si aile hekiminin, \%89,6'sı aile sağlığı çalışanının şimdiye kadar ev ziyaretinde bulunmadığını belirtmiştir. Ölü doğum ve bebek ölümlerinin \%95,9'unun doğumu hastanede; \%1'inin sağlık ocağında ve \%3,1'inin doğumu evde yapılmıştır. Hastanedeki doğumların \%74,9'u doktor ve \%25,1'i ebe tarafından yaptırılmıştır.

Ölü doğum ve bebek ölümlerinin tanısı olarak \%28' erken doğum; \%15,5'ine masere ölü doğum, \%14'üne doğumsal anomali ve \%10,4'üne doğumsal kalp hastalığı yazıımıştır; \%11,9'unun ölüm nedeni belli değildir. 2005 yılında ölü doğum ve bebek ölümlerinin \%17,1'inin ölüm nedeni belli değildir. 2008 yılı için bu yüzde 1,8'dir. Ölü doğumu ve bebek ölümü olan ailelerin \%68,9'u alt, $\% 20,7$ 'si orta sosyal sınıf, \%8,8'i işsiz ve \%1,6'sı üst sosyal sınıfta yer almaktadır. Üst sosyal sınıftaki ölümlerin tamamı ölü doğumdur (hiç bebek ölümü olmamıştır). Alt sosyal sınıfta ölü doğum ve bebek ölümlerinin \%30,1'i erken doğum, \%15,8'i masere ölü doğum, \%14,3'ü doğumsal anomali ve \%10,5’i doğumsal kalp hastalığıdır (Tablo 2). 


\begin{tabular}{|c|c|c|c|c|c|}
\hline & 2005 & 2006 & 2007 & 2008 & 2005-2008 \\
\hline \multicolumn{6}{|l|}{ Ölçütler } \\
\hline Ölü Doğum Hızı & 2,3 & 1,2 & 2,6 & 7,1 & 3,3 \\
\hline Perinatal ölüm hızı & 7,6 & 5.6 & 7,6 & 15,0 & 8,9 \\
\hline Erken yenidoğan ölüm hızı & 5,2 & 4,7 & 4,7 & 8,0 & 5,6 \\
\hline Geç yenidoğan ölüm hızı & 1,4 & 2,3 & 2,0 & 2,5 & 2,0 \\
\hline Post yenidoğan ölüm hızı & 2,1 & 3,4 & 2,0 & 2,3 & 2,4 \\
\hline Bebek ölüm hızı & 8,8 & 10,8 & 9,3 & 12,8 & 10,4 \\
\hline \multicolumn{6}{|l|}{ İlçeler-bebek ölüm hızları } \\
\hline Merkez & 9,7 & 10,7 & 9,0 & 11,8 & 10,3 \\
\hline Akçakoca & 2,5 & 9,0 & 4,6 & 11,4 & 6,8 \\
\hline Cumayeri & 5,0 & 5,4 & 20,4 & 14,2 & 11,2 \\
\hline Çilimli & - & 8,0 & 4,0 & 3,9 & 4,0 \\
\hline Gölyaka & 12,0 & 4,0 & 7,6 & 10,7 & 8,5 \\
\hline Gümüşova & 5,6 & 9,8 & 10,6 & 4,7 & 7,6 \\
\hline Kaynaşlı & 10,6 & 8,8 & 11,2 & 17,2 & 11,9 \\
\hline Yığılca & 16,6 & 28,8 & 15,0 & 34,7 & 23,6 \\
\hline
\end{tabular}

*Hızları doğru hesaplamak için 2005 ve 2008 yılları arındaki tüm ölü doğum ve bebek ölümleri katılmıştır (256 kişi)

Tablo 2. Düzce'deki ölü doğumların ve bebek ölümlerinin nedenlerinin yıllara ve sosyal sınıfa göre yüzde dağılımı*

\begin{tabular}{|c|c|c|c|c|c|c|c|c|c|}
\hline \multirow{2}{*}{$\begin{array}{l}\text { Ölü doğum ve bebek } \\
\text { ölümü nedeni }\end{array}$} & \multicolumn{4}{|c|}{ Yıllar } & \multicolumn{5}{|c|}{ Sosyal sınıf } \\
\hline & $\begin{array}{l}2005 \\
(n=35)\end{array}$ & $\begin{array}{l}2006 \\
(n=44)\end{array}$ & $\begin{array}{l}2007 \\
(n=58)\end{array}$ & $\begin{array}{c}2008 \\
(n=56)\end{array}$ & $\begin{array}{l}\text { Üst } \\
(n=3)\end{array}$ & $\begin{array}{c}\text { Orta } \\
(n=40)\end{array}$ & $\begin{array}{c}\text { Alt } \\
(n=133)\end{array}$ & $\begin{array}{c}\text { İşsiz } \\
(n=17)\end{array}$ & $\begin{array}{l}\text { Toplam } \\
(n=193)\end{array}$ \\
\hline & & & & \multicolumn{2}{|c|}{$\%^{\star \star}$} & & & & \\
\hline $\begin{array}{l}\text { Masere ölü doğum } \\
(n=30)\end{array}$ & 22,9 & 6,8 & 19,0 & 14,3 & 33,3 & 15,0 & 15,8 & 11,8 & 15,5 \\
\hline $\begin{array}{l}\text { Taze ölü doğum } \\
(n=13)\end{array}$ & - & - & 5,2 & 17,9 & 66,7 & 10,0 & 5,3 & - & 6,7 \\
\hline Erken doğum $(n=54)$ & 22,9 & 38,6 & 24,1 & 26,8 & - & 25,0 & 30,1 & 23,5 & 28,0 \\
\hline $\begin{array}{l}\text { Doğumsal anomali } \\
(\mathrm{n}=27)\end{array}$ & 17,1 & 13,6 & 8,6 & 17,9 & - & 12,5 & 14,3 & 17,6 & 14,0 \\
\hline $\begin{array}{l}\text { Doğumsal } \\
\text { kalp hastalığı } \\
(\mathrm{n}=20)\end{array}$ & 5,7 & 15,9 & 10,3 & 8,9 & - & 12,5 & 10,5 & 5,9 & 10,4 \\
\hline $\begin{array}{l}\text { Sepsis } \\
(n=9)\end{array}$ & 2,9 & 4,5 & 8,6 & 1,8 & - & 7,5 & 4,5 & - & 4,7 \\
\hline $\begin{array}{l}\text { Perinatal asfiksi } \\
(n=9)\end{array}$ & 5,7 & 2,3 & 3,4 & 7,1 & - & 7,5 & 3,3 & 11,8 & 4,7 \\
\hline $\begin{array}{l}\text { ASYE } \\
(n=4)\end{array}$ & 5,7 & 2,3 & 1,7 & - & - & - & 2,3 & 5,9 & 2,1 \\
\hline $\begin{array}{l}\text { Menenjit enfeksiyonu } \\
(n=2)\end{array}$ & - & - & 2,3 & 1,7 & - & 2,5 & 0,8 & - & 1,0 \\
\hline $\begin{array}{l}\text { Doğum travması } \\
(n=1)\end{array}$ & - & - & - & 1,8 & - & - & 0,8 & - & 0,5 \\
\hline $\begin{array}{l}\text { Ani bebek ölümü } \\
(n=1)\end{array}$ & - & - & - & 1,8 & - & - & 0,8 & - & 0,5 \\
\hline $\begin{array}{l}\text { Ölüm nedeni } \\
\text { belli değil }(n=23)\end{array}$ & 17,1 & 13,6 & 17,2 & 1,8 & - & 7,5 & 12,0 & 23,5 & 11,9 \\
\hline Toplam (n=193) & 100,0 & 100,0 & 100,0 & 100,0 & 100,0 & 100,0 & 100,0 & 100,0 & 100,0 \\
\hline Toplam $(n=193)^{\star \star \star}$ & 18,1 & 22,8 & 30,1 & 29,0 & 1,6 & 20,7 & 68,9 & 8,8 & 100,0 \\
\hline
\end{tabular}

* 01.01.2005-30.09.2008 tarihleri arasındaki ölümler; ** sütun yüzdesi; ** satır yüzdesi

ASYE: Alt solnum yolu enfeksiyonu 
Ölü doğumu ve bebek ölümü olan annelerin \%23,3'ünün kendiliğinden düşüğü, \%13,5'inin isteyerek düşüğü, \%3,6'sının daha önceden ölü doğumu ve \%8,2'sinin daha önceden bebek ölümü olmuştur. Ölü doğum ve bebek ölümü olan annelerin \%72'sine (2005-2008 yılları arasında sirasıyla $\% 65,7, \% 70,5 ; \% 70,7$ ve $\% 78,6)$ gebelikleri öncesinde aile planlaması bilgisi verilmemiştir. 2005-2008 yılları arasında bu gebeliği hiç istememe $\% 9,3$ 'tür. Annelerin \%39,9'u sağlık kurumuna ya da sağlık personeline ilk kez üç ay ve üzerinde gebe iken başvurmuşlardır. Annelerin \%41,6'sının bir önceki gebelikleri ile ölü doğum ve bebek ölümü olan gebelikleri arasındaki süre iki yılın altındadır. Ölü doğan ve ölen bebeklerin doğum ağırlıkları \%46,5'inde 2500 gram ve üstündedir. Annelerin \%47'sinin gebelik süresi 37-40 hafta arasındadır (Tablo 3).
2005-2008 yılları arasında ölü doğum ya da bebek ölümü olan annelerin kim tarafından izlendiğine dair veriler Tablo 4'te verilmiştir. 2005 yllında ölü doğumu ve bebek ölümü olan annelerin aile hekimi tarafından ortalama izlem

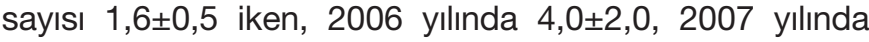
$4,3 \pm 1,8$ ve 2008 yilında $4,8 \pm 1,9$ olmuştur.

Ölü doğumu ve bebek ölümü olan annelerin \%94,5'inin kan basıncı ölçümü, \%81,9'unun ultrason muayenesi yapılmıştır. Ölü doğum ve bebek ölümü olan annelerin \%69,4'ü lohusalık dönemlerinde hiç izlenmemiştir (Tablo 5).

\section{Tartışma}

Düzce Illinde sağlık hizmet örneğinin değişim yıllarında (2005-2008) bebek ölüm hızı binde 8,8-12,8 arasındadır. Düzce İlinde bebek ölüm hızını, Türkiye Nüfus ve Sağlık Araştırması (TNSA) 2008 Türkiye geneli ölüm hızları

\section{Tablo 3. Ölü doğumu ve bebek ölümü olan annelerin gebelik durumu}

\begin{tabular}{|c|c|c|c|}
\hline & & $\mathbf{n}$ & $\%$ \\
\hline \multirow[t]{2}{*}{ Kendiliğinden ya da kendi çabası ile düşük hiç oldu mu? } & Evet & 45 & 23,3 \\
\hline & Hayır & 148 & 76,7 \\
\hline \multirow[t]{2}{*}{ İsteyerek düşük hiç oldu mu? } & Evet & 26 & 13,5 \\
\hline & Hayır & 167 & 86,5 \\
\hline \multirow[t]{2}{*}{ Daha önce hiç ölü doğumu oldu mu? } & Evet & 7 & 3,6 \\
\hline & Hayır & 186 & 96,4 \\
\hline \multirow[t]{2}{*}{ Daha önce hiç bebek ölümü oldu mu? } & Evet & 16 & 8,2 \\
\hline & Hayır & 177 & 91,8 \\
\hline \multirow[t]{3}{*}{ Bu gebeliği isteme durumu } & İstemiş & 144 & 74,6 \\
\hline & Daha sonra istemiş & 31 & 16,1 \\
\hline & Hiç istememiş & 18 & 9,3 \\
\hline \multirow[t]{2}{*}{ Bir önceki gebeliği ne zaman oldu (yıl) } & $2<$ & 80 & 41,6 \\
\hline & $2 \geq$ & 113 & 58,4 \\
\hline \multirow[t]{2}{*}{ Gebe kalmadan önce aile planlaması bilgisi verme } & Evet & 54 & 28,0 \\
\hline & Hayır & 139 & 72,0 \\
\hline \multirow[t]{2}{*}{ Doktora ya da sağlık kurumuna ilk başvuruda kaç aylık hamile olunduğu } & $3<$ & 116 & 60,1 \\
\hline & $3 \geq$ & 77 & 39,9 \\
\hline \multirow[t]{5}{*}{ Gebelik süresi* $^{\star}$} & 22-24 hafta & 20 & 10,4 \\
\hline & 25-30 hafta & 42 & 21,8 \\
\hline & 31-36 hafta & 34 & 17,6 \\
\hline & $37-40$ hafta & 93 & 48,2 \\
\hline & 41-42 hafta & 4 & 2,1 \\
\hline \multirow[t]{4}{*}{ Doğum ağırlığı** } & $600-1000 \mathrm{gr}$ & 43 & 22,8 \\
\hline & $1001-2000 \mathrm{gr}$ & 36 & 19,0 \\
\hline & $2001-2500 \mathrm{gr}$ & 22 & 11,6 \\
\hline & $2501-5000 \mathrm{gr}$ & 88 & 46,5 \\
\hline \multirow[t]{2}{*}{ Şu an gebelik var mı } & Evet & 15 & 7,8 \\
\hline & Hayır & 178 & 92,8 \\
\hline Toplam & & 193 & 100,0 \\
\hline
\end{tabular}

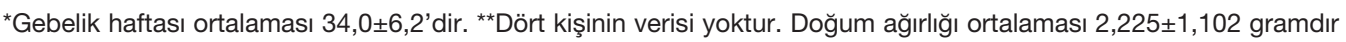


(bebek ölüm hızı 1000 canlı doğumda 17; yaşamın ilk bir ayında ölme olasılığı binde 13, sonraki 11 ayda binde 4) ve yine aynı araştırmadan elde edilen Düzce'nin de dâhil olduğu 22 ilin bebek ölüm hızları ile (bebek ölüm hızı 1000 canlı doğumda 22; yaşamın ilk ayında ölme olasılığı binde 12 sonraki 11 ayda binde 9) karşılaştırdığımızda, Düzce'deki bebek ölüm hızının daha düşük olduğu görülmüştür. Bunun önemli nedenlerinden biri TNSA 2008'in 2003 ve 2004 yıllarını da kapsamasıdır. TNSA 2008 çalışmasında Türkiye'de bebek ölüm hızında son yıllarda fark edilir bir azalma saptanmıştır. Nitekim TNSA 2008 çalışmasında 1998-2003 ile
2003-2008 yılları arasındaki beş yıllık dönemde bebek ölüm hızının \% 48 azaldığı belirtilmiştir (7). İkinci önemli neden TNSA 2008 çalışmasındaki ölüm hızı verilerin sadece bir ile ait olmamasıdır. Bu durum, il düzeyinde karşılaştırma yaparken TNSA verilerinin intiyatla yorumlanması gerektiğini düşündürmektedir.

Düzce il merkezi ve ilçelere göre bebek ölüm hızlarının hesaplanması ile bebek ölüm hızının sosyoekonomik etkenden etkilendiği ve sağlıkta eşitsizliği yansıtan önemli bir gösterge olduğu ortaya çıkmaktadır. Düzce Illinin Yığılca İlçesinde bebek ölüm hızının merkeze ve diğer ilçelere göre daha yüksek olduğu göze çarpmaktadır. Yığılca

Tablo 4. Ölü doğumu ve bebek ölümü olan annelerin gebelikleri sürecindeki izlemleri

\begin{tabular}{|c|c|c|c|c|c|c|}
\hline & & İzlem yok & 1-3 izlem & 4 izlem & 5 ve üstü izlem & $\begin{array}{l}\text { Ortalama } \pm S S^{*} \\
\text { (en az-en çok) }\end{array}$ \\
\hline & & & & $\%$ & & \\
\hline \multirow{5}{*}{$\begin{array}{l}2005 \\
(n=35)^{\star}\end{array}$} & SO & 60,0 & 2 & - & 17,1 & $3,5 \pm 2,6(1-7)$ \\
\hline & KDU & 14,3 & 34,3 & 25,7 & 25,8 & $3,8 \pm 1,8(1-8)$ \\
\hline & $\mathrm{AH}$ & 91,4 & 8,6 & - & - & $1,6 \pm 0,5(1-2)$ \\
\hline & ASÇ & 91,4 & 8,6 & - & - & $1,6 \pm 0,5(1-2)$ \\
\hline & Toplam & 5,7 & 20,0 & 14,3 & 60,0 & $6,2 \pm 3,2(1-14)$ \\
\hline \multirow{4}{*}{$\begin{array}{l}2006 \\
(n=44)\end{array}$} & KDU & 18,2 & 31,7 & 13,6 & 36,4 & $4,8 \pm 3,2(1-18)$ \\
\hline & $\mathrm{AH}$ & 15,9 & 38,7 & 6,8 & 38,4 & $4,0 \pm 2,0(1-10)$ \\
\hline & ASÇ & 15,9 & 41,0 & 6,8 & 36,3 & $3,9 \pm 2,1(1-10)$ \\
\hline & Toplam & 2,3 & 9,1 & 6,8 & 81,8 & $11,2 \pm 6,2(1-30)$ \\
\hline \multirow{4}{*}{$\begin{array}{l}2007 \\
(n=58)\end{array}$} & KDU & 17,2 & 31,1 & 13,8 & 37,8 & $4,4 \pm 2,4(1-14)$ \\
\hline & $\mathrm{AH}$ & 6,9 & 29,4 & 13,8 & 50,0 & $4,3 \pm 1,8(1-7)$ \\
\hline & ASÇ & 6,9 & 22,4 & 15,5 & 55,1 & $4,6 \pm 1,7(1-7)$ \\
\hline & Toplam & 1,7 & 3,4 & - & 94,9 & $12,2 \pm 5,1(2-23)$ \\
\hline \multirow{4}{*}{$\begin{array}{l}2008 \\
(n=56)\end{array}$} & KDU & 3,6 & 30,4 & 14,3 & 51,8 & $5,1 \pm 3,8 \quad(1-20)$ \\
\hline & $\mathrm{AH}$ & 17,9 & 23,2 & 8,9 & 50,1 & $4,8 \pm 1,9(1-10)$ \\
\hline & ASÇ & 16,1 & 21,5 & 10,7 & 51,9 & $4,9 \pm 1,9(1-10)$ \\
\hline & Toplam & - & 7,2 & 1,8 & 91,0 & $13,0 \pm 5,9(1-31)$ \\
\hline
\end{tabular}

SO: Sağlık Ocağı; KDU: Kadın Doğum Uzmanı; AH: Aile Hekimi; ASÇ: Aile Sağlığı Çalışanı; İılemi olanlar arasında

Tablo 5. Ölü doğumu ve bebek ölümü olan annelerin gebelik sürecinde yapılan ișlemler ( $n=193)$

Doktor ya da sağlık kurumunca gebelik sürecinde yapılan işlemler

\begin{tabular}{|c|c|c|}
\hline & $\begin{array}{c}\text { Evet } \\
\mathbf{n}\end{array}$ & $\begin{array}{c}\text { Evet } \\
\%\end{array}$ \\
\hline Vücut ağırlığı ölçümü & 185 & 95,9 \\
\hline Boy uzunluğu ölçümü & 141 & 73,1 \\
\hline Kan basıncı ölçümü & 187 & 96,9 \\
\hline Kan tahlili yapılması & 178 & 92,2 \\
\hline İdrar tahlili yapılması & 172 & 89,1 \\
\hline Karın ölçümü & 172 & 89,1 \\
\hline Bebeğin kalp atışını dinleme & 182 & 94,3 \\
\hline Ultrason muayenesi & 158 & 81,9 \\
\hline Lohusa takibi & 59 & 30,6 \\
\hline
\end{tabular}

*Hızları doğru hesaplamak için 2005 ve 2008 yılları arındaki tüm ölü doğum ve bebek ölümleri katılmıştır (256 kişi) 
sosyoekonomik olarak gelişmişlik açısından Türkiye'deki ilçeler $(n=832)$ arasında 746. sırada yer almaktadır (8). Bebek ölüm hızının en düşük olduğu yerleşim birimlerinden biri sıralamada 98. sırada olan Düzce II Merkezidir. Bebek ölüm hızının sosyoekonomik etmenlerden etkilendiği ve sosyoekonomik düzeyi düşük olan bölgelerde perinatal, yenidoğan, bebek ve beş yaş altı ölüm hızlarının yükseldiğine ilişkin pek çok çalışma bulunmaktadır (9-16). Düzce İlinde aile hekimliği uygulamasına geçilmesine rağmen, alt sosyal sınıflar hala risk altında olduğundan, bu riski azaltacak yaklaşımlara gereksinim olduğu görülmektedir.

Bebeği ölen ya da ölü doğum yapan annelerin sağlık güvencesine bakıldığında alt sosyoekonomik gurupta yer alan hanelerde daha fazla bebek ölümü yaşandığı söylenebilir; çünkü Türkiye'de yeşil kart sahibi olma ya da sağlık sigortasının olmaması alt sosyal sınıfı yansıtan önemli göstergelerdir. Nitekim bu çalışmada ölü doğumu ve bebek ölümü olan ailelerden yeșil kartılıarın ve sağlık sigortası olmayanların hemen hemen hepsi sosyal sınıf açısından ya alt sosyal sınıfta ya da işsizler içinde yer almıştır. Düzce Illinde 2008 yllında ölü doğumu ve bebek ölümü olan annelerin \%28,5'i ya yeşil kartlı ya da sağlık sigortasız iken, aynı yılda hastane kayıtlarına göre Düzce'de doğum yapan yaklaşık 5000 kadında bu yüzde 16,2'dir.

Düzce ilinde yenidoğan döneminde meydana gelen ölümler bebek ölümlerinin yüzde \%73,1'ini oluşturmaktadır. Bu yüzde TNSA 2008'de 76; Konya'da 2007 yılında \%72,3'tür (17). Üst gelir ülkelerinin büyük çoğunluğunda $(n=56)$ ve Türkiye'nin de içinde yer aldığı üst-orta gelir grubu ülkelerin $(n=42)$ bir kısmında bebek ölümlerinin yaklaşık olarak \%75'i yenidoğan döneminde; \%25'i yeni doğan dönemi sonrasında meydana gelmektedir (18-20). Bu durumda, Düzce'deki bebek ölümlerinin yenidoğan dönemi ve yeni doğan dönemi sonrası dağılımının üst gelir grubu ülkelerin verileri ile benzer olduğunu söyleyebiliriz.

Düzce Illinde bebek ölümlerinin yenidoğan dönemi ve yeni doğan dönemi sonrası yüzde dağılımının üst gelir grubundaki ülkelerle koşut olmasına rağmen, bebek ölüm hızına baktığımızda Düzce'de binde 10'un üzerinde olan bebek ölüm hızının üst gelir grubundaki ülkelerdeki (yaklaşık binde 5) bebek ölüm hızından daha yüksek olduğunu görüyoruz. Bu yüksekliğin ana nedeni yenidoğan dönemi sonrası ölüm hızından (üst gelir grubu ülkelerde yenidoğan dönemi sonrası ölüm hızı yaklaşık binde 1,3; Düzce'de 2005-2008 yılları arasında binde 2,4) çok yenidoğan döneminin ölüm sayısının fazla olmasıdır. Bu çalışmada erken yenidoğan ölümlerinin bebek ölümlerindeki payı \%53,8'dir. Türkiye'de yapılan diğer araştırmalarda erken yenidoğan ölümlerin bebek ölümleri içindeki oranı \%38 ile \%58 arasında değişmektedir (21-23). Üçüncü basamak sağlık kurumunda bu yüzde 74,8'e çıkmaktadır (24).

Ölü doğum ve bebek ölüm hızlarının daha fazla düşmemesinde ve son yıllardaki artışlarında üreme sağlığı hizmetlerinin istenen düzeyde olmayışının etkisini göz ardı etmemek gerekmektedir. 2005 yilında ölü doğumu ve bebek ölümü olan yaklaşık her üç kadından ikisine gebelik öncesinde aile planlaması yöntemleri konusunda sağlık çalışanı tarafından bilgi verilmemesi; 2008 yılında bu oranın her dört kadından üçüne çıkması; 2008 yılında gebeliği hiç istememe yüzdesinin 2005 yılına göre iki katına çıkması; ölü doğumu ve bebek ölümü olan annelerin \%23,3'ünün kendiliğinden, \%13,5'inin isteyerek düşük yapması, üreme sağlığı hizmetlerinin yeterince verilmediğini düşündürmektedir. Nitekim Özcan ve ark.'ları (25) tarafından Düzce'de yapılan çalışmada üreme sağlığı hizmetlerinde özellikle aile planlaması yönteminde 2005 ile 2007 yılları arasında bir azalma olduğu belirtilmiştir. Sağlık Müdürlüğü verilerini incelediğimizde de aile planlaması hizmetlerinde 2008 ortalarına kadar bir gerileme yaşandığı görülmektedir. Özellikle bu çalışmadan sonra aile planlamasında yaşanan sorunların açık bir şekilde ortaya çıkması ile üreme sağlığı merkezince ilde aile hekimliği birimlerinde çalışan tüm doktorlar, ebe ve hemşireler aile planlaması, gebe izlemi, bebek izlemi konularında sürekli bir hizmet içi eğitime tabi tutulmuştur ve bu eğitim çalışmaları devam etmektedir. Gebe izlemi, bebek izlemi, aile planlaması verilerinde bir düzelme eğilimi ortaya çıkmaya başlamıştır. Yine de bu süreci daha sağlıklı değerlendirmek için 2010 ya da 2011 yıllarının bitmesini beklemek gerektiğini düşündürmekteyiz.

Aile hekimliği uygulamasında 15-49 yaş kadın izlem zorunluluğunun olmaması gebe ve bebek tespitlerinin yapılamamasına ve gebelik açısından risk taşıyan kadınların saptanamamasına neden olmaktadır. Koruyucu hizmetlerin alanda sürdürülmesinden vazgeçilmiş, hizmet sadece başvuranlar ya da çağrıldığında gelenler ile sınırlandırıımıştır. Nitekim bu çalışmada ölü doğumu ve bebek ölümü olan her on anneden sadece biri evde ziyaret edildiğini bildirmiştir.

Bu çalışmada, ölü doğumu ya da bebek ölümü olan annelerin gebelik dönemlerinde aile hekimi ve aile sağlığı çalışanı tarafından dört ya da beş kez izlendiği saptandı. Bu sayının en önemli nedeni Sağlık Bakanlığı'nın gebelik boyunca dört kez izlemi yeterli görmesi ve gebe izlem sayısının dördün altında olması halinde ücret kesintisi yapmasıdır (26). Sağlık Bakanlığının risk grubu içerisinde yer alan gebelerin daha fazla izlenmesini sağlayacak bir uygulama getirmesi gerektiği düşünülebilir; ancak bir taraftan da bu gebelerin kadın doğum uzmanları tarafından ortalama beş kere izlendiği göz önüne alınırsa izlem sayısının yeterli olduğu söylenebilir. Bu çalışmada 2005 yılından 2008 yılına doğru geldikçe hem aile sağlığı merkezi hem de kadın doğum uzmanı tarafından izlenme sayılarının arttığı saptanmıştır. Bu izlemlerde gebelerin vücut ağırığı, kan basıncı, idrar ve kan tahlillerinin yaklaşık \%90 ve ultrason muayene izlemlerinin \%80 (2008 yllı için \%92,3) oranında yapıldığı gözlenmiştir. 2005 yılından 2008 yılına kadar yapılan testlerde ve özellikle kadın doğum uzmanının izleminde sayısal bir artış olmakla birlikte, bu artışın olumlu yansımalarını somutlaştırmamamızın nedeni 2005 yılında yapılmış test ve izlemlerin istenen düzeyde değilse bile belli bir düzeyi yakalamış olmasıdır. Nitekim doğum öncesi bakım sırasında yapılan izlem, test ve ölçümlerin yüksek olmasını bebek ölüm nedenleri ile birlikte göz önüne aldığımızda Düzce'de önlenebilir bebek ölüm nedenlerinin 
azaltılmasına katkı sağladığı söylenebilir. Türkiye Nüfus ve Sağlık Araştırması-2008 araştırmasında da doğum öncesi bakım sırasında yapılan bu testlerin ve ölçümlerin \%90 civarında olduğu TNSA 2008'de, TNSA 2003'teki değerlere göre belirgin bir şekilde daha yüksek olduğu belirtilmiştir (7). Kuşkusuz doğum öncesi bakım sırasında yapılan testler ve ölçümler erken tanı ile bebek ölüm hızının düşürülmesinde önemli bir rol oynamaktadır. Doğum öncesi bakım erken, geç ve yenidoğan dönemi sonrası ölüm hızını azaltmaktadır (27). Gebeliği sırasında yeterli doğum öncesi bakım alan annelerde daha az ölü doğum ve bebek ölümü olmaktadır (28-31).

Doğum öncesi bakımdaki bu niceliksel artışın niteliksel yönü göz ardı edilmemesi gereken bir konudur. Ölü doğumu ve bebek ölümü olan annelerin \%69,4'ünün lohusalık dönemlerinde hiç bir izlem yapılmamış olması, taze ve masere ölü doğum sayısının artışı, bebek ölüm nedenleri arasında prematüre ölümün yüksekliği ve her 10 anneden dördünün bir sağlık kurumuna ilk kez gebeliklerinin üçüncü ayından sonra gitmeleri, izlemlerin niteliksel açıdan değerlendirilmesi gerektiğini göstermektedir.

Düzce'de 2005-2008 yılları arasında meydana gelen bebek ölüm nedenlerinin sıklık sırası erken doğum, doğumsal anomali, doğumsal kalp hastalığı, perinatal asfiksi, sepsis ve alt solunum yolu enfeksiyonudur. Özelikle 2008 yılında alt solunum yolu enfeksiyonu ve sepsis sayılarının diğer yıllara göre düşmesi önlenebilir bebek ölümlerinde yol alındığını göstermektedir. Sağlık Bakanlığı 1998 yılı istatistiklerine göre, bebeklik dönemi ölümlerinin ilk üç nedenini sırasıyla pnömoni $(\% 48,4)$, ishal $(\% 23,7)$ ve solunum yolu enfeksiyonları $(\% 10,8)$ oluşturmaktadır $(32)$. Türkiye'de 2000 yılından sonraki çalışmalarda zaman içinde erken doğum, doğumsal anomali, doğumsal kalp hastalığı, perinatal asfiksi gibi ölüm nedenlerinin ön plana çıktığını, enfeksiyonlara bağlı ölüm nedenlerinin ise gerilediği görülmektedir (21-23,33-36). Bu durum, hem Düzce hem Türkiye'de ölüm nedenlerinin bir dönüşüm sürecine girerek yüksek gelir grubu ülkelerin ölüm nedenleri ile büyük bir oranda benzerlik gösterdiğini düşündürmektedir (18-20). Bu yakınlığın ortaya çıkmasında yeni doğan bakım hizmetlerindeki iyileşmelerin katkısı önemlidir; ancak öte yandan erken doğuma bağlı ölüm sıklığının gelişmiş ülkelere göre Düzce'de yüksek olmasında yeni doğan bakım hizmetlerindeki eksikliklerin etkisi yadsınamaz. Nitekim 2008 yılına kadar Düzce'de yeni doğan bakım birimi bulunmamaktaydı.

Ölü doğum ve bebek ölümlerinin yaklaşık yarısının 37-40 gebelik haftasında meydana gelmesi, yine her iki bebekten birisinin 2500 gramın üzerinde doğması hem doğum öncesi bakımın niteliğini hem de doğum sürecini ve sonrasını da sorgulatmak gerektiğini düşündürmektedir. ABD'de 2002 yılında ölen bebeklerin \%95'i hem 32 gebelik haftasında hem de 1500 gramın altındadır (37). Türkiye'de son yıllarda yeni doğan yoğun bakımı alanındaki teknolojik gelişmeler, mekanik ventilatör kullanımında artış ve yeni kuşak antibiyotiklerin yaygınlaşması çok düşük doğum ağırlıklı (<1500 gram) bebeklerin ölüm oranını gelişmiş ülkeler seviyesine getirmemekle birlikte azaltmıştır (38-39).

II geneli bebek ölüm hızının 2005 yılında en düşük olmasının önemli nedenlerinden biri 2005 yılının Ocak ayında Düzce'de aile hekimliği çalışmalarına başlanmasından dolayı birinci basamak sağlık çalışanlarının aile hekimliği sürecindeki geleceklerine yoğunlaşması ile saha çalışmalarının, kayıt ve bildirim sisteminin aksamasıdır. Nitekim bu çalışmada 2005 yılında tespit edilen ölü doğumların ve bebek ölümlerinin yaklaşık üçte ikisinin hiç izlenmediği saptanmıştır. 2005 yılında ölü doğum ve bebek ölüm hızının düşük çıkmasının bir başka nedeni de aile hekimliği sürecinden bağımsız, geçmişten bu yana bebek ölüm kayıtlarının tam ve doğru bildirilmemesi olabilir. Bu durum 2006 ve 2007 yılı için de kısmen geçerlidir. Tüm Türkiye'de bu sorunun çözümü için Sağlık Bakanlığı 6 Mayıs 2005'te bir genelge (sayı: 78) ile her ölü doğum ve bebek için "Bebek Ölüm Kayıt-Bildirim Formu"nun doldurulmasını zorunlu tutmuş; tüm sağlık kurumlarında bu konu üzerinde hassasiyetle durulmasını istemiştir. Bu genelde Ocak 2007 tarihinde güncellenmiştir (40). Düzce'de özellikle 2007 yılından başlayarak ölü doğum ve bebek ölüm kayıtlarının tam ve doğru olması için tüm birinci, ikinci ve üçüncü basamak sağlık kurumlarında yoğun bir hizmet içi program uygulanmıştır. Nitekim II Sağlık Müdürlüğünün 2008 yılına ait kayıtlarını, aile hekimlerinin, hastanelerin, nüfus ve mezarlık müdürlüklerin kayıtları ile karşılaştırdığımızda ölüm bildirim ve kayıtlarında bir sorun olmadığı tespit edilmektedir.

\section{Sonuç}

Düzce İli genel olarak Türkiye'de gelir düzeyi oldukça iyi bölgeler arasında yer almakla beraber il içinde yer alan düşük sosyoekonomik düzeydeki ailelerde bebek ölümleri daha fazla görülmektedir.

Bu çalışmada aile hekimliği uygulamasında üreme sağlığı (aile planlaması) hizmetlerindeki aksaklıklar tespit edilmiştir. Aile hekimliği uygulamasında gözlenen bu açıklıkların düzeltilmesi gerekir.

Bebek ölüm nedenlerinin önlenebilmesi için intrauterin ve yenidoğan dönemine ilişkin sağlık hizmetlerinin niteliksel olarak iyileştirilmesine gereksinim olduğu görülmektedir; ancak alt sosyoekonomik düzeydeki ailelerde halen yenidoğan dönemi sonrasına ait sağlık sorunlarının da bebek ölümlerine neden olduğu gözden kaçırılmaması gereken bir noktadır.

Teşekkür: Çalışmaya katkılarından dolayı Düzce Sağlık Müdürü Dr. Bahattin İlter, Düzce AÇS-AP Şube Müdürü Dr. Emel Oğuz’a, Düzce Sağlık müdürlüğünde görevli Kadriye Taşkaya, Nesrin Doğan'a ve Düzce Toplum Sağlığı merkezlerinde çalışan Ayşegül Kaya, Zuhal Eroğlu, Evrim Kahraman, Rukiye Cesur, Gönül Bademlik, Ayşe Dursun Sezgin, Bircan Türedi, Nurhan Şengül ve Semra Demirel'e teşekkür ederiz.

Çıkar çatışması: Bildirilmedi. 


\section{Kaynaklar}

1. Sağlık Bakanlığı. Aile hekimliği Türkiye Modeli. 1.Baskı. Ankara: Mavi Ofset Yayınları, 2004: 35-40. (PDF)

2. Aile Hekimliği Pilot Uygulaması Hakkında Kanun. Kanun No: 5258, Kabul Tarihi: 24.11. 2004. Resmi Gazete'de Yayımlandığı Tarih: 09.12. 2004. Sayı: 25665.

3. Aile Hekimliği Pilot Uygulaması Hakkında Yönetmelik. Resmi Gazete'de Yayımlandığı Tarih: 06.07.2005, Sayı: 25867. (PDF)

4. Nesanır N, Erkman N. Evaluation of this process on healt Indicators of 11 provinces practicing model of family medicine firstly. TAF Prev Med Bull 2010; 9: 400-9.

5. Hacettepe Üniversitesi Nüfus Etütleri Enstitüsü, Türkiye Nüfus ve Sağlık Araştırması, 2003. Hacettepe Üniversitesi Nüfus Etütleri Enstitüsü, Sağlık Bakanlığı Ana Çocuk Sağlığı ve Aile Planlaması Genel Müdürlüğü, Devlet Planlama Teșkilatı ve Avrupa Birliği, Ankara, Türkiye, 2005: 109-18. (Abstract)

6. Boratav K. Sınıfların ve grupların sosyoekonomik nitelikleri. 2.baskı. Ankara: İmge Kitapevi Yayınlar; 2004: 33-60.

7. Hacettepe Üniversitesi Nüfus Etütleri Enstitüsü, Türkiye Nüfus ve Sağlık Araştırması, 2008. Hacettepe Üniversitesi Nüfus Etütleri Enstitüsü, Sağlık Bakanlığı Ana Cocuk Sağlığı ve Aile Planlamas Genel Müdürlüğü, Başbakanlık Devlet Planlama Teşkilatı Müstesarlığı ve TÜBiTAK, Ankara, Türkiye. Hacettepe Üniversitesi Hastaneleri Basımevi tarafından basılmıştır Yayın No: NEE-HÜ.09.01ISBN 978-975-491-274-6. 2009; 134: 144-213.

8. Dinçer B, Özaslan M. İlçelerin sosyo-ekonomik gelişmişlik sıralaması araştırması. 1.baskı. Ankara: DPT Yayınları; 2004: 117-30. (PDE)

9. Singh GK, Kogan MD. Persistent socioeconomic disparities in infant, neonatal, and postneonatal mortality rates in the United States, 1969-2001. Pediatrics 2007; 119: 928-39. (Abstract) / (Full Text) / (PDF)

10. Jorgensen T, Mortensen LH, Nybo Andersen AM. Social inequity in fetal and perinatal mortality in the Nordic countries. Scand J Public Health 2008; 36: 635-49. (Abstract)

11. Stephansson O, Dickman PW, Johansson ALV, Cnattingius S. Influence of socioeconomic status on stillbirth risk in Sweden. Int J Epidemiol 2001; 30: 1296-301.

12. Gissler M, Rahkonen O, Arntzen A, Cnattingius S, Andersen A-M N, Hemminki E. Trends in socioeconomic differences in Finnish perinatal health 1991-2006. J Epidemiol Community Health 2009; 63: 420-5. (Abstract) / (Full Text) / (PDF)

13. Zhuochun Wu, Viisainen $\mathrm{K}$, Wang $\mathrm{Y}$, Hemminki E. Perinatal mortality in rural China: retrospective cohort study. BMJ 2003; 327: 1319-22. (Abstract) / (Full Text) / (PDF)

14. Størdal K. Neonatal mortality--the key to reduced neonatal mortality? Tidsskr Nor Laegeforen 2009; 129: 2270-3. (Abstract) / (PDF)

15. Khang $\mathrm{YH}$. Relationship between childhood socioeconomic position and mortality risk in adult males of the Korea Labour and Income Panel Study (KLIPS). Public Health 2006; 120: 724-31. (Abstract) / (Full Text) / (PDF)

16. Rand NS. Urbanization, development and under five mortality differentials by place of residence in Sao Paulo, Brazil, 1970-1991. Labor and Population Program. Working Paper Series 02-13. Santa Monica. Rand's Publications, 2002: 2-14. (PDF)

17. Bodur S, Durduran Y, Küçükkendirci H, Dogan C. Relationship of infant mortality with prenatal and natal service utility and demographic characteristics: case-control study. Dicle Medical Journal 2009; 36: 288-93. (Abstract)

18. World Health Organization. The World Health Report 2005: Make Every Mother and Child Count. Geneva:WHO Pub, 2005. ISBN 9789241563734 (NLM classi. cation: W 84.6), 2005: 174-90. (Abstract)

19. Neonatal and perinatal mortality: country, regional and global estimates 2004. Geneva, World Health Organization Pub 2007; 1-19. (Abstract)
20. Life tables for WHO Member States. Geneva, World Health Organization, 2009

21. Okyay P, Atasoylu G, Meteoglu D, Demiröz H, Coobanoglu M, Beser E. Infant deaths and stillbirths in Aydin province in 2004 Journal of Adnan Menderes Üniversity Medical Faculty 2006; 7: 3-12.

22. Karabulut A, İstanbullu B, Karahan T, Özdemir K. Two year evaluation of infant and maternal mortality in Denizli. JTGGA 2009; 10: 95-8. (Abstract)

23. Balcı $E$, Küçük E, Gün I, Gülgün $M$, Kıllç $B$, Cetinkaya $K$. Neonatal deaths at Melikgazi at Kayseri in 2006. Firat University Medical Journal of Health Sciences 2008; 22: 323-6.

24. Dolly AY. İstanbul Üniversitesi Cerrahpaşa Tıp Fakültesi Çocuk Sağlığı ve Hastalıkları Anabilim Dalı'nda 2000-2006 yıllarında ölen olquların değerlendirilmesi. Turk Ped Ars 2007; 42: 148-52. (Abstract) / (Full Text)

25. Özcan C, Töre E, Kut A, Simşek D, Erdal R. Comparison of the differences in the provision of the primary health care services in Düzce before and after regional pilot Implementation of the family medicine. J Health Community 2008; 18: 25-31.

26. Aile Hekimliği Pilot Uygulaması Hakkında Yönetmelik. Resm Gazete'de Yayımlandığı Tarih: 06.07.2005; Sayı: 25867. (PDF)

27. Volpe FM, Abrantes MM, Capanema FD, Chaves JG. The impact of changing health indicators on infant mortality rates in Brazil, 2000 and 2005. Rev Panam Salud Publica 2009; 26: 478-84. (Abstract) / (PDF)

28. Biri A, Öztürk J, Maral I. Maternal deaths occured in hospitals in Ankara between 1997 and 2000. T Klin J Med Sci 2002; 22: 142-7. (Abstract) / (PDF)

29. Bezircioğlu İ, Çetinkaya B, Biçer M, Baloğlu A. Risk factors associated with intrauterıne fetal death. Turkiye Klinikleri $J$ Gynecol Obst 2007; 17: 14-7.

30. Tıraş Ü, Saç R, Tazegül A, Dallar Y, Bıyıklı Z. Social and clinical characteristics of nonsurvivors treated in our neonatal intensive care unit. Turkiye Klinikleri J Pediatr 2007; 16: 151-7. (Abstract) / (PDF)

31. Göksever H, Kılıç B, Erata Y. Epidemiologic factors in preterm birth. Turkiye Klinikleri J Gynecol Obst 2008; 18: 294-305. (Abstract) / (PDF)

32. TC Ministry of Health-UNICEF. situation of children and women in Turkey report, Ministry of the Government-UNICEF program of cooperation 2001-2005. Ankara: Sağlık Bakanlığı Yayınları: ISBN 92-806-3665-5, 2000: 125.

33. Avcı A, Topuzoğlu A. Research on causes of mortality among children under age 5 in Istanbul in 2005 TAF. Prev Med Bull 2008: 7: 301-10. (Full Text) / (PDF)

34. Ünsal A, Metintaş S, Inan Ç, Arslantaş D, Tözün M, Çetin E. Infant mortality rate and mortality reasons in Eskişehir. Osmangazi Medical Journal 2005; 27: 9-14.

35. Özbek A.E, Karabiber H. The rates and causes of child mortality between 1999 and 2004 in the province center of Kahramanmaraş. Journal of Kahramanmaraş Sütçü Üniversity Medical Faculty 2004; 1: 50-4.

36. Öztürk A, Gün I, Öztürk Y. The evaluation of infant deaths occurring in Kayseri. Erciyes Medical Journal 2002;24:14-22.

37. Callaghan WM, MacDorman MF, Rasmussen SA, Qin C, Lackritz EM. The contribution of preterm birth to infant mortality rates in the United States. Pediatrics 2006; 118: 1566-73. (Abstract) / (Full Text) / (PDF)

38. Türkmen M, Altıncık A, Acar C, Tosun A, Aydoğdu A. Outcome of very low birth weight infants followed in the neonatal intensive care unit of Adnan Menderes University Faculty of Medicine. Journal Of Adnan Menderes Üniversity Medical Faculty 2006; 73: 3-6.

39. Bülbül $A$, Füsun Okan $F$, Sahin $S$, Nuhoğlu $A$. Düșük doğum ağırlıklı erken doğmuş bebeklerde erken dönem hastalık ve ölüm oranı sonuçları. Turk Ped Ars 2008; 43: 94-8. (Abstract) / (Full Text) / (PDF)

40. Sağlık Bakanlığı'nın 6.05.2005 tarihli 78 sayılı "Bebek ölümleri Bilgi Formu" genelgesi. 